\title{
The Effects of a Multicomponent Motivational System Intervention Using Peer-Tutoring for Implementation on the Automation of Single-Digit Addition Tasks of Four Struggling Elementary Students
}

\author{
Jennifer Karnes * and Matthias Grünke
}

check for

updates

Citation: Karnes, J.; Grünke, M. The Effects of a Multicomponent

Motivational System Intervention

Using Peer-Tutoring for

Implementation on the Automation of Single-Digit Addition Tasks of Four Struggling Elementary Students. Educ. Sci. 2021, 11, 265. https:// doi.org/10.3390/educsci11060265

Academic Editor: James Albright

Received: 7 May 2021

Accepted: 26 May 2021

Published: 27 May 2021

Publisher's Note: MDPI stays neutral with regard to jurisdictional claims in published maps and institutional affiliations.

Copyright: (c) 2021 by the authors. Licensee MDPI, Basel, Switzerland. This article is an open access article distributed under the terms and conditions of the Creative Commons Attribution (CC BY) license (https:/ / creativecommons.org/licenses/by/ $4.0 /)$.
Department of Special Education \& Rehabilitation, University of Cologne, 50923 Cologne, Germany; matthias.gruenke@uni-koeln.de

* Correspondence: jennifer.karnes@uni-koeln.de; Tel.: +49-221-4702147

\begin{abstract}
Derived math fact fluency becomes more imperative across all mathematical content areas during a students' mathematics development. However, many of them struggle to automate the most basic math facts sufficiently and therefore are not able to deal with more complex mathematical problems. This leads to the fact that many of them are already left behind in the early years of their school careers whether they have diagnosed learning disabilities or not. In this single-case research project, we evaluated a peer-tutoring approach designed to extend the number of automated singledigit addition tasks for four struggling elementary students through a multicomponent motivational system including immediate correction of errors, graphical feedback on performance, positive reinforcement, direct instruction flashcards, and a racetrack game. A multiple-baseline design (ABE) across subjects was applied to assess the effects of the treatment. The results indicate significant and large effects of the intervention on the number of automated math facts for the participants. This substantiates the assumption that the math-fact recall performance of struggling students can be improved through the method of peer tutoring even with the limited resources available in everyday school life.
\end{abstract}

Keywords: automation; basic math fact fluency; learning difficulties; peer-tutoring; math racetracks; DI flashcards

\section{Introduction}

\subsection{The Importance of Addition Fact Fluency}

Good basic math skills are essential for both school and personal life. They are indispensable for succeeding in various subjects (e.g., science, social studies, and of course, math), and we need them to handle many life tasks such as managing our finances. However, the significance of basic math skills goes beyond the immediately obvious: They help us to develop our logical and critical thinking in general. Analyzing and solving problems would not be possible without this ability. Calculation skills bring order to almost every aspect of life and enable us to orient ourselves in a complex society [1-4].

Unfortunately, far too many individuals struggle with math from childhood all the way into adulthood. This holds them back in many ways. For example, they do not earn the formal qualifications during their lives that they would otherwise have received and often enter low-paying careers [2,4-6]. The problems begin early in life and usually become evident during the first year of school. Currently, a large percentage of elementary and secondary students does not meet minimal standards in the area of math. They struggle even with basic arithmetic. According to the 2019 National Assessment of Educational Progress, about $40 \%$ of all students score below the benchmark set for defining fundamental calculation skills [7]. Here, a more nuanced look is necessary at how the struggle of not being able to make adequate progress in developing more complex concepts, such as 
overcoming counting-on, is a substantial predictor for less computational flexibility in particular, as well as mathematical achievements in general [8,9]. This circumstance underlines the relevance of classroom instruction in overcoming this hurdle in students' early school years.

Many of the problems these young people demonstrate concern their lack of knowledge of basic math facts $[10,11]$. Students need to show sufficient fluency in this respect to be able later to tackle more complex mathematical operations successfully [12,13]. Math fact fluency is defined as the ability to answer simple facts in addition, subtraction, multiplication, and division accurately and rapidly [14]. According to Steel and Funnell [15], students who have not reached adequate fluency entering sixth grade will not be likely to catch up on this backlog. The reason is that automated retrieval eases the very limited capacities of the human working memory [6]. Automation enables learners to use their cognitive resources to solve more complex math problems later in their development [16-18]. Therefore, acquiring these skills to an advanced level by the end of elementary school is decisive for their continuing school careers.

Of the four basic arithmetical operations, addition is most primary. Understanding the underlying concept presupposes different insights: It begins with a deep comprehension of what a number represents and what its connection is with other numbers. Later, children pass through different strategies: count-all, count-on, maximum addend, minimum addend. As soon as an awareness of the basal principles of this operation has sunk in, automatic fact retrieval can be built up [19]. However, this last step seems to be particularly challenging for many elementary school children [20].

\subsection{Ways to Foster Math Fact Fluency}

Luckily, research has identified some effective strategies to foster math fact fluency and thus pave the way for promising school careers without severe problems in arithmetic [3,4,21-25]. Some of the most effective approaches involve (1) immediate correction of errors, (2) graphical feedback displaying previous performance, (3) verbal praise that attributes high performance to effort and low performance to various reasons, (4) direct instruction flashcards, and (5) racetrack games.

Immediate correction of errors prevents students from committing a mistake to memory. Different findings demonstrate that such feedback needs to occur immediately after an accurate response, not after completing an entire worksheet [26,27]. The graphical feedback displaying previous performance gives a student the chance to monitor his or her own performance individually. This self-monitoring has been demonstrated in different findings to be highly motivating due to the fact that low performers are finally able to compete successfully by doing so against their own previous performance [28-30]. Using verbal praise that attributes high performance to effort and low performance to various reasons is a well-grounded approach to maintain or increase learners' motivation to engage as it divides performance into internal stable attribution (e.g., results are due to my engagement, my strategies, my preparation) and into external and unstable attribution (e.g., the weather had a bad influence, there was an exhausting class before the performance). This attribution supports the emotional connection of personal effort and augmented competencies [31,32]. The direct instruction flashcards provide a procedure for struggling students to automate and memorize certain information and therefore benefit in recalling this content [33,34]. Finally, the racetrack method uses a game board with a number of cells. To move forward and reach the goal of the game board, the student must solve, for example, a math task (or, e.g., read a word aloud or spell a word, depending on the learning content) [34-36].

In conclusion, the aforementioned methods do not focus on building an understanding of mathematical operations but rather presuppose this already. They focus on the subarea of automation in order to achieve increases in performance and therefore in motivation to further engage in learning with a positive attitude toward mathematics and, in addition, relief of the working memory. This achieves the long-term goal of creating more capacity for more complex tasks $[25,37,38]$. 


\subsection{Peer Tutoring as a Means to Implement Effective Interventions under Real-Life Conditions}

Even though these elements seem simple and plausible, teachers still face challenges as they try to implement them in their daily classroom routines. It is not easy to provide sufficient time for engaging students in practice activities while providing enough opportunities for responding and immediate feedback. Complicating matters, Burns et al. [39] mentioned that students have different rates for acquiring tasks as well as initial ratios of known and unknown facts varying from student to student over time to achieve math-fact fluency. Therefore, individualized instruction and methods that take the special needs of students into account are vital to enabling professionals to teach more effectively.

This is where peer tutoring can come to the rescue. Peer tutoring is defined as the process of one student helping another to learn and master some aspect of the curriculum. One is taking on the role of a teacher, instructing another either at the same academic level or lower $[40,41]$. Peer tutoring can be implemented in a peer-assisted one-to-one setting [42] or as class-wide or total-class peer tutoring [43,44]. The impact on students performance is, among other aspects, linked to the time actively engaged with the academic task $[45,46]$, as well as to the frequency with which immediate feedback regarding students performance is possible [46].

Current research generally describes peer tutoring as effective for tutor and tutee, across settings such as general and special education or alternative education, for students with and without disabilities as well as students with different native languages $[47,48]$. It has already been examined and proven effective for different learning contents such as reading, writing, and arithmetic [49-51].

\subsection{Research Question}

Several factors altogether lead to the aim of this study: the aforementioned aspects concerning struggling students' need for instruction and close monitoring; their lack of time actively engaged in academic tasks; the need to automate basic math facts to successfully develop more complex computing competencies; and the results of the current research concerning the increase in student performance using racetracks, direct instruction flashcards, immediate feedback, explicit timing, and positive reinforcement, as well as those concerning the effectivity of the peer-tutoring method. Therefore, this study examines the effects of a peer-tutoring intervention combined with the use of racetracks, direct instruction flashcards, and explicit timing in combination with immediate feedback and positive reinforcement on the automation of single-digit addition tasks of four struggling elementary students.

\section{Method}

\subsection{Participants and Setting}

The study was conducted in an inclusive elementary school in a large city in North Rhine-Westphalia. In it, children are taught in so-called family classes together with students from the first to the fourth grade. Following the class teacher's suggestion, a preselection of possible participants was tested to identify suitable participants. The following inclusion criteria were determined as the basis for this selection: (a) basic understanding of single-digit addition tasks, (b) automation of the single-digit addition tasks of less than $10 \%$, (c) regular school attendance over the last six months, (d) student willingness to take part in the intervention, and (e) being socially capable of independently working with a partner without needing constant attention from an adult.

To find students eligible for the study, a class-wide standardized assessment of math operation skills (Heidelberg Math Test 1-4 [HRT 1-4] by Haffner et al.) [52] was applied, different from a non-standardized paper-pen assessment concerning the automation of the single-digit addition tasks with all second- to fourth-grade students. Despite weaknesses concerning the automation of the single-digit addition tasks (range from zero to three tasks), four students reached a percentile between 20 and 43 in the HRT 1-4 concerning their addition skills, which means they may be described as at the borderline of competency. 
Therefore, they were chosen to be trained as tutees, according to the fact that they met all other inclusion criteria as well. Those students chosen as tutees were tested concerning known but not automatized single-digit addition tasks and answered the German version of the standardized Math Anxiety Questionnaire by Thomas and Dowker [53] to determine whether they were eligible for the training.

The tutors were chosen on the basis of their results in the HRT 1-4, where they had to reach at least the 50th percentile. Additionally, the teacher had to consider them socially capable of taking responsibility for accompanying a fellow student. Those four tutors were then assigned to a partner from the tutees on the basis of their results in the pretest as well as their social connections with the tutees, which should be neither a close friendship nor a problematic relationship. All four tutees were born and raised in Germany and had no diagnosed learning disabilities. As this study focuses on the results for the tutees, the tutors will not be described further.

The first team was Anton (tutee, age 7) and René (tutor) (all names have been changed to comply with data protection regulations). Anton's teacher described him as curious and motivated to participate in the training. On the other hand, he was easily distracted, but it was not difficult to turn his attention back to his tasks. He reached the 20th percentile in the HRT 1-4 test, and his scores in the Math Anxiety Questionnaire were the lowest of all participants, but still did not mark him as having math anxiety. Anton was able to solve $69.44 \%$ of the single-digit paper-pen test, but like all participants, solved zero tasks in the oral test within two seconds.

The second team consisted of Berta as the tutee (age 7) and Barbara as tutor. According to her teacher, Berta behaved introvertedly but still participated willingly during training sessions. She was focused on her tasks and did not distract herself noteworthily. She achieved the highest results in the HRT 1-4 in the 43rd percentile and was able to solve $75 \%$ of tasks correctly in the paper-pen test.

Celina (age 7) worked together in a team with Stephanie. Her teacher characterized her as lively and open. She always looked forward to the next training session. Celina was highly engaged in improving her timing when playing racetracks. Like Berta, she was focused and not easily distracted. Celina reached the 20th percentile in the HRT 1-4 and $84.72 \%$ in the paper-pen test.

The fourth and last team consisted of Diana (age 8) as tutee and Monika as tutor. Her teacher viewed her as introverted and quiet. However, she was still willing to make an effort, stayed focused, and was not easy to distract. She had $97.22 \%$ correct answers on the paper-pen test and reached the 35th percentile in the HRT 1-4.

\subsection{Experimental Design}

An ABE multiple-baseline design was conducted across subjects [54]. The data were collected in a period of 10 weeks with 19 measurements in total and an average of three probes per week. The $\mathrm{ABE}$ design allows control of internal validity such as maturation or history [55]. Taking the SCRIBE guidelines by Tate et al. [56] into account, the start of the intervention was staggered randomly to increase internal validity. In addition to that, each phase in the design had to include at least three measurement points. Accordingly, the training started between the 6th and the 9th probe. The assignment via random dragging with put-back resulted in Celina and Anton having 5 days', Diana 6, and Berta 8 days duration in the baseline. Consequently, Celina and Anton received 11, Diana 10, and Berta 8 training sessions. There were three weeks between the last treatment and the follow-up phase, which lasted three days for all cases.

\subsection{Dependent Variable and Measurement}

As dependent variable, the common intersection of unautomated single-digit addition tasks among the participants was determined through preselection. To this purpose, PowerPoint slides were presented containing a pool of 55 single-digit addition tasks (excluding 0 and reverse tasks). Each slide with one task was displayed for two seconds and 
then crossfaded by a neutralizing slide. This happened to keep the participant motivated to solve the missing tasks but without having further pressure due to the tracking of their response time. The oral answers were noted on a protocol sheet using the following classification of the possible given answers: "correct within two seconds," "counted correct (more than two seconds)," "wrong," "wrong with correction," and "no answer." From this pool of 55 items, the intersection of 28 different single-digit tasks without their reversals remained as not automated among overall students. The 27 tasks remaining from the pool of 55 items reviewed could be assumed to be automated by at least one participant, which, if included in the grant, could potentially have skewed the results. Therefore, these 27 tasks were not included in the training. Moreover, the measurements over all data points consisted of those 28 tasks randomly allocated for each measurement. Additionally, randomization of assignments between record sheets for each data point and participant was applied to improve the internal validity.

\subsection{Materials and Procedures}

Three graduate students created an instruction manual together with the first author in order to obtain a detailed description for every step of the intervention. For each training session, a PowerPoint presentation with a set consisting of the intersection of non-automated single-digit addition tasks over all participants was prepared in random order of the tasks as measurement (randomization per tutee as well as session). The random assignment was conducted with respect to the order of the tasks per set, the assignment to the measurement, as well as with respect to the student for which the test was performed. Each slide with a task disappeared after two seconds for the interventionists to control whether the answer was given in an automated way or the participant was able to solve the task by counting. As in the determination of the non-automated facts described before, the same neutralizing slide was placed between two slides and a protocol sheet with the same five categories as described before for each of these tests was conducted.

The items were printed on flashcards (half the size of a postcard) as to be seen in Figure 1 on thick opaque paper with the task itself on the front and the task including the sum on the back. In addition to that, the racetrack likewise to be seen in Figure 1 was printed on thick paper twice the size of a worksheet. This racetrack included 28 cells from the starting point to the finishing cell and had running figures for identification and motivation imprinted on them. Furthermore, a stopwatch was used to document the duration for one round on the racetrack. In addition, a line diagram was provided for students to monitor their own performance during the intervention. Together with the line diagram, the personal high score was noted on a small sheet by the tutee and put on top of each participant's individual folder, which they received at the beginning of the intervention.
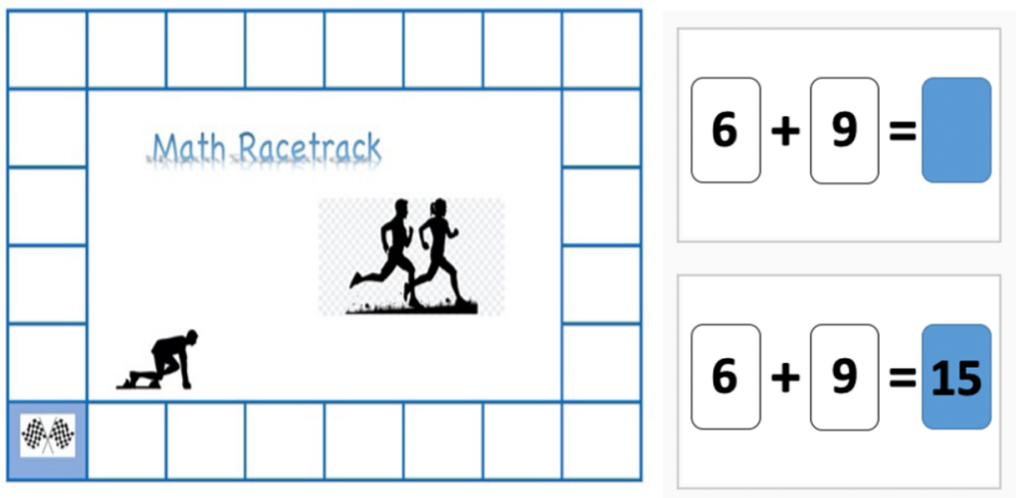

Figure 1. Racetrack game board and DI flashcard example showing front and back.

During the baseline (phase A), each tutee was taken out of the classroom and into a separate room, where two measurements (and later, two interventions) had to be conducted 
simultaneously. This was due to school organization issues, yet all students managed to work properly and without remarkable disturbance. The number of single-digit addition tasks orally solved correctly within two seconds functioned as the dependent variable and was noted by the interventionist each day. Therefore, the measurement via PowerPoint presentation of not-automated 28 single-digit addition tasks for the tutee was carried out, where the math facts had to be solved as quickly and correctly as possible while the interventionist wrote the results down on the protocol sheet. Afterwards, the tutor also entered the room, and tutee and tutor read texts for $15 \mathrm{~min}$ to control the impact of attention through the interventionists and to keep conditions of both phases as similar as possible. No further treatment was implemented at that point.

With the beginning of the intervention, the procedure stayed the same, and the training sessions started with the measurement of the tutees. Differing from conditions in the baseline, the line diagram was presented to increase the students' motivation and make their individual progress visible. Further, the interventionist gave feedback in relation to previous results, which was either attributed to effort (in case of an increase in the students' performance) or to external influences such as bad weather or bad general conditions on that day (in case of stagnation or even deterioration). After that, the tutor was brought to the room, where the training using the direct instruction flashcards, the racetrack, and the procedure for tutee and tutor were implemented by the interventionist. After a demonstration of the procedure, the interventionist observed the tutors and the tutees training and immediately corrected whenever they did not adhere exactly to the agreement. Tutees were told that they were competing with themselves, being as fast as possible at the destination of the playing field through solution of the math tasks as quickly and at the same time as correctly as they could.

The deck of 28 flashcards was placed in front of the tutor, concealed by hand. The tutor then raised one flashcard after the other to the tutee with the side on which the task was shown. On the back, the tutor could see the task itself as well as the correct answer, and the tutee had to name the task and result correctly. In that case, the tutor gave immediate positive feedback and handed the card to the tutee. If the task was solved incorrectly, the tutor presented the correct task and its solution, directly instructing as a model, and replaced the flashcard in the third place in the deck of flashcards, to be repeated soon. Meanwhile, the tutee was asked to repeat the task and the correct answer, thereby building the problem-answer association. When a task appeared again, the tutor increased the tutee's focus by saying something like, "Let's see if you still remember that task." Training ended when the tutee had received all flashcards. This procedure reinforced near-term repetition after direct instruction, including repetition, and therefore supported students in trying to remember the solution to the task.

After all the items were recalled and trained by means of the flashcards, the participants played the racetrack game. Thus, they were again asked to solve the tasks, but this time with a more inviting game character supplemented with time measurement, which increased the motivation of students to answer as quickly and correctly as possible. To play the racetrack game, the flashcards were reshuffled, and again the tutor covered them by hand. The game board was directed to the tutee, including the playing piece on the starting field. As soon as the participant was ready, the tutor started the timing and showed the tutee all flashcards one after the other. Again, the tutee had to state the task and solution correctly. If they succeeded in doing so, they could move the playing piece one field forward. If they answered incorrectly, the tutor asked them to have a closer look at the task. If they still could not answer correctly, the tutor named the correct task and solution, and the tutee had to repeat it. This procedure was implemented to further engage participants not only to move as fast as possible but also to answer correctly. After this, the playing pieces were also moved one field forward. The timing ended when the participant had processed all 28 tasks and reached the target field.

The tutor noted the measured lap time on the protocol sheet with positive feedback. If the time was a personal best, it was noted as a new high score for the participant, 
accompanied by further positive feedback. The interventionist finished the session after about $15 \mathrm{~min}$, giving the tutor and tutee feedback concerning their cooperation. After that, all children returned to their classes.

\subsection{Treatment Fidelity and Social Validity}

Three 60 min training sessions were conducted to instruct three graduate students in the correct implementation of the intervention. Furthermore, they received a 24-item checklist to ensure the quality of implementation during the treatment (list is available on request). All aforementioned factors to be considered were included in this checklist. The assistants randomly observed the interventions distributed to all participants for more than $80 \%$ of all measurements during the implementation. If an aspect was not fulfilled during the training session, the observing assistant corrected the course following the instructions from the manual after the treatment session ended.

After the last intervention, the interventionists interviewed each participant individually to collect data in the form of a questionnaire concerning the social validity of the treatment. Therefore, the participants were asked whether (a) they enjoyed the training with the math racetrack, (b) the math racetrack helped them solve the tasks, (c) they could solve single-digit addition tasks better now, (d) they liked receiving immediate feedback on their performance, (e) they were looking forward to working with the math racetracks, (f) they would like to proceed in working with the math racetracks, and (g) they liked working with a partner and found it helpful. The interventionists supported the students in filling out the questionnaire by reading the questions aloud.

\section{Results}

\subsection{Visual Analysis}

As can be seen in the graphs created with the SCAN package in R by Wilbert [57] in Figure 2 as well as in Table 1 concerning the descriptive scores for the correctly solved addition tasks of each participant, all participants increased their number of correctly solved single-digit addition tasks within two seconds compared to the number of the same addition tasks correctly counted before the intervention. In all cases, the scores improved visibly after the onset of the intervention. With the exception of Celina, no score during the intervention fell below the ones during phase A. Still, overall scores in phase B variability had to be recorded for all cases, and no participant finished the intervention with a personal high score. Anton, Berta, and Diana show a change in level, whereas in Celina's case a slope appeared with the implementation of the training. The mean baseline difference [58] as an index, which does not calculate the non-overlap effect sizes, was applied, where an average increase of about $471 \%$ was recorded. Celina benefitted the most, with a mean baseline of $627.5 \%$, and Diana the least, but still considerably with $222.5 \%$. Even if an increase in performance was evident for all participants, Anton, Berta, and Celina demonstrated the most impressive enhancements concerning the mean baseline difference. Regarding the maintenance data, no further increase in performance took place in three cases. Only Celina scored her maximum during this phase. The other participants all reached their high scores from the B phase also during maintenance, or were slightly below it.

Table 1. Descriptive scores for correctly solved items for each participant.

\begin{tabular}{ccccccc}
\hline & $\mathbf{n}(\mathbf{A})$ & $\mathbf{n ~ ( B )}$ & $\mathbf{n ~ ( E )}$ & $\mathbf{M}(\mathbf{A}) \mathbf{S D}$ & $\mathbf{M}(\mathbf{B}) \mathbf{S D}$ & $\mathbf{M}$ (E) SD \\
\hline Anton & 5 & 11 & 3 & $1.60(1.30)$ & $10(2.93)$ & $12.67(1.15)$ \\
Berta & 8 & 8 & 3 & $1(0.93)$ & $6.13(2.80)$ & $6.33(2.08)$ \\
Celina & 5 & 11 & 3 & $1.20(1.09)$ & $8.78(5.12)$ & $15.33(1.53)$ \\
Diana & 6 & 10 & 3 & $2(0.63)$ & $6.45(1.77)$ & $6.33(0.58)$ \\
\hline
\end{tabular}



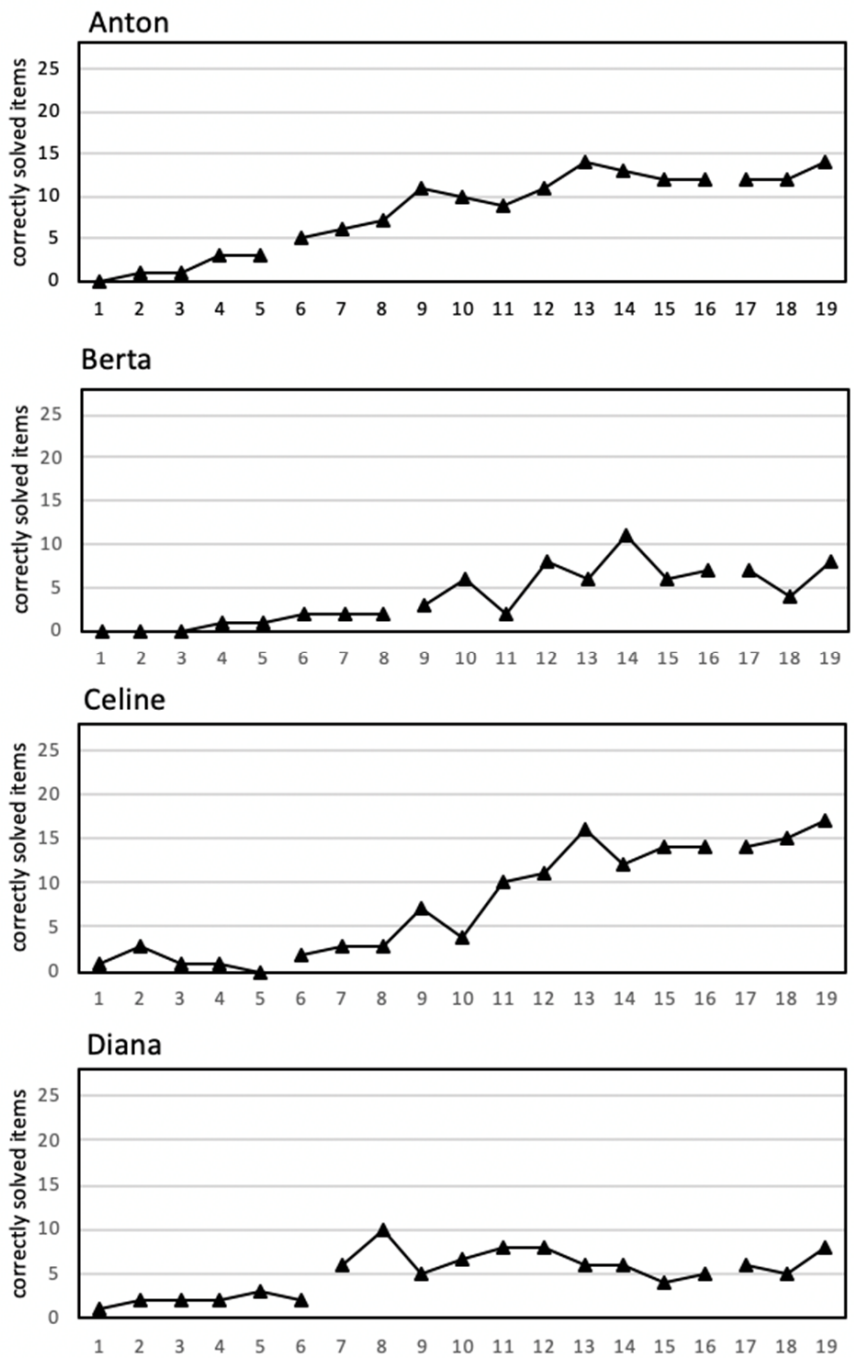

Figure 2. Number of correctly solved single-digit addition items in phases A, B, and E for each participant.

\subsection{Quantitative Analysis}

Table 2 presents the descriptive statistics for the number of correctly solved singledigit addition facts within two seconds for each participant. Some of the most common and reliable non-overlap effect sizes were calculated again using the SCAN package by Wilbert [57] with non-overlap of all pairs (NAP), which compares each data point of the intervention phase with each data point of the baseline and therefore provides a reliable effect size and Tau-U. This in turn has the ability to analyze data independently for several phases showing contrasts in a single-case design and is able to combine non-overlap and trend [59]. The treatment can be documented as effective due to both indices. From phase A to phase B, all participants showed great improvement. Diana showed the least improvement. Still, NAP as well as Tau-U showed significant differences between phases $A$ and $B$ for all students.

Table 2. Effect sizes for the number of correctly solved items.

\begin{tabular}{cccccc}
\hline & Tau-U corrected & $p$ & NAP & $p$ & MBD \\
\hline Anton & 0.63 & $0.001^{* *}$ & 100 & $0.001^{* * *}$ & $525.0 \%$ \\
Berta & 0.43 & $0.019^{*}$ & 97.66 & $0.000^{* * *}$ & $512.5 \%$ \\
Celina & 0.84 & $0.000^{* *}$ & 96.36 & $0.002^{* *}$ & $627.5 \%$ \\
Diana & 0.27 & $0.144^{* * *}$ & 100 & $0.001^{* *}$ & $222.5 \%$ \\
\hline
\end{tabular}

Note. NAP = non-overlap of all pairs, MBD = mean baseline difference. ${ }^{*}$ Significant at the 0.05 level, ${ }^{* *}$ significant at the 0.01 level, ${ }^{* * *}$ significant at the 0.001 level. 
To substantiate the aforementioned indices, and in accordance with the standards for single-case research by Tate et al. [56] calling for a broader examination of the outcomes than visual inspection and the calculation of the effect sizes, a piecewise regression analysis on level 2 (across all participants) as to be seen in Table 3 was also conducted. This allows more reliable statements if the data follow different trends over different participants by pointing out connections between the data concerning the change in data from baseline to intervention as well as if there is a slope or level effect to be mentioned. As seen in these results, there was a significant level effect from phase A to B on the 0.05 level, as well as a significant slope effect on the 0.01 level.

Table 3. Piecewise regression level 2 analysis.

\begin{tabular}{ccccc}
\hline & $\boldsymbol{B}$ & $\boldsymbol{S E}$ & $\boldsymbol{t}$ & $\boldsymbol{p}$ \\
\hline Intercept & 2.18 & 2.10 & 1.04 & 0.30 \\
Trend & 0.15 & 0.38 & 0.40 & 0.69 \\
Level Phase B & 1.44 & 1.54 & 0.94 & 0.53 \\
Level Phase E & 13.39 & 5.03 & 2.66 & 0.01 \\
Slope B & 1.01 & 0.42 & 2.58 & 0.01 \\
Slope E & -0.25 & 1.11 & -0.23 & 0.82 \\
\hline
\end{tabular}

Anton, Berta, and Celina stated that they enjoyed the training with the math racetrack a lot, whereas Diana liked it only a little. They all gave the feedback that the math racetrack helped them solve the tasks and that they could solve single-digit addition tasks better than before. Furthermore, they all liked receiving immediate feedback on their performance and liked working with a partner, which they also stated unanimously was helpful. Again, Diana was the only one who was looking forward only a little to working with the racetracks, whereas the others strongly looked forward to it during the period of intervention.

\section{Discussion}

\subsection{Main Findings}

The purpose of this single-case study was to examine the effects of a peer-tutoring intervention using math racetracks, direct instruction flashcards, and explicit timing, all combined with immediate feedback and positive reinforcement on the number of automated single-digit addition tasks of four struggling elementary school students. The results facilitated the interpretation that the intervention can be considered an appropriate way to help struggling students successfully automate basic facts through implantation by peers in the role of tutors. The remarkable magnitude of increase in performance went from $222.5 \%$ as the lowest to $627.5 \%$ as the highest. On an individual basis, the different utilized effect sizes were notable for all participants, and the used indices stated large to very large effects. Finally, a regression analysis at level 2 confirmed the previous results and therefore underlined the benefits of using peer tutoring on the performance of the participants.

Regarding Diana's less-notable results in comparison to the other participants, it should be mentioned that she and her tutor did not harmonize well and that she was dealing with difficult circumstances in her private environment, which she reported during the treatment. Another reason for the different rate of improvement across a multiple baseline design could be found in the suggestion that some students who are over-reliant on counting-base strategies might improve less than others [60]. Still, she was able to increase her performance, albeit to a lesser extent.

Moreover, these results fit well with previously described effects for both peer tutoring [49-51] as well as math racetracks [34-36] on the performance of struggling students. Still, this study is to be considered unique in combining both easy-to-implement methods in one intervention added to further motivational components. These findings are also substantial for future implantation by teachers because it did not take long for the students to increase their performance significantly. 
In particular, the students stated in the social validity questionnaire that they enjoyed their own improvement. Overall, the responses from the participants on the social validity questionnaire indicated a high degree of acceptance of the intervention using the math racetrack in a peer-tutored setting. No negative comment on the instruction was given, and only Diana twice answered in a more reserved way with "a little bit," and none of the answers of any participant was "no." According to the class teacher, they even seemed to act more confident in math classes after the intervention.

\subsection{Limitations}

Regardless of the aforementioned promising results, there are also limitations to this study. First, large-scale generalizability is not given due to the small sample examined in single case studies. Following the standards for single-case research by Tate et al. [56], this limitation can be countered by replications of the study. According to the prescription of these standards, for an intervention to be considered evidence-based, it requires at least five methodologically sound case reports with positive effects and at least 20 participants across all studies. Therefore, this study can only be considered a prelude for further single-case research examining the effects of peer-tutoring intervention combined with the use of math racetracks to increase student performance. Nevertheless, the results should not be considered isolated from the positive effects described in the aforementioned research to both peer tutoring as well as math racetracks and have to be regarded as an important supplement to the previous findings.

In addition, no data were collected that would allow any conclusions to be drawn as to the exact influence that each of the two methods had on the performance itself. Moreover, the additionally implemented motivational aspects such as use of a personal high score, corrective feedback, and a line diagram cannot be analyzed separately concerning their individual impact on the results. To determine the respective source of the positive outcomes more specifically, an alternating treatment design comparing, for example, the racetracks, the flashcards, and the peer tutoring could give more detailed information about the degree of influence of each aspect of the multicomponent motivational intervention. Besides the missing data concerning each method itself, no data were collected on the impact the intervention had on the tutors' performance. Although these were selected in advance based on their higher performance, a closer look at the effects of the treatment would also have been a desirable addition. The selection, assignment, and methodical monitoring of the tutors was not checked more closely, which could have provided important information about the success of the teams, the tutees, and the tutors, as well. Furthermore, the data sets could have been presented more precisely, including the comparison of the total number of correctly solved items to those correctly solved within two seconds. The operation skills concerning addition itself, however, were already in the inclusion criteria, as were the items examined as facts known by all participants but not yet automated by any of them. In addition to that, the time needed for the students to finish their racetracks had been stopped but not recorded as further data to underline the students' improvement. Future research should focus on the extent of the impact the training has on the time needed to finish the game board.

Finally, missing data concerning the incorrect answers is an important limitation as it does not allow a more accurate interpretation of the students' performance. This could have been given, for example, by using a digital version of the racetrack, collecting data about which tasks were solved incorrectly and which were solved correctly, or by the interventionists collecting these data in a hidden way using a protocol sheet as they did during measurement.

\subsection{Practical Implications and Future Research}

The results of this research support efforts to offer teachers additional reasons to use these methods to increase the number of automated single-digit addition facts in low-performing students. Even if the results cannot join the ranks of previous studies 
due to the expansion to include peer tutoring to bring them closer to being evidencebased related to the standards described in SCRIBE [56], they still should be used as supplementation to previous results, as the use of peer tutoring provides further clarity on the method's suitability in challenging situations where teachers try to accommodate every level of learning.

This also represents one of the greatest advantages of the implemented economic method of the racetracks, as it is simple for teachers to implement, and-as this study highlighted-it also encourages peers to work together. Besides the simplicity of the implementation, the content is easily customizable to any learning content needed through, for example, small changes in the use of mathematical facts. Thus, if a struggling student needs to automate multiplication facts instead of single-digit addition tasks, this method is easily adaptable to his or her individual needs.

Follow-up research should investigate the extent of each aspect of this multicomponent motivational intervention more closely as well as the particular influence of the racetracks themselves compared to the peer-tutoring setting. In addition, further research should try to meet more of the standards for single-case studies, such as SCRIBE [56], so that researchers may finally be able to call the method evidence-based. In addition, the effects on the tutors' performance should be considered in order to determine whether and to what extent they could also benefit from training in tasks they were already more familiar with than the tutees. Not only should future researchers take into account the tutors' math competencies, but they should take a closer look at the impact on social skills, taking into account a methodical, continuous monitoring and training of the tutors with the aim of discovering whether it is possible to maximize profit for them as well.

Finally, but more relevant and current than ever, a digital version of the racetracks should be developed. This should not be difficult to achieve, as the digital approach is a promising one for increasing student motivation even more than the existing, implemented motivational aspects. In the area of digital support services concerning math fluency interventions, there is great need for further offerings on one hand and even more need for research meeting scientific standards on the other [20]. Besides the fact that digital learning seems to have a motivating effect, the need to support the development of digital skills in all students is an obvious one, with digitalization increasing in all sectors of society.

All in all, the racetrack, in combination with the multicomponent motivational system, is not only easy to implement, but also encourages peers to work together. Tutees as well as tutors enjoyed it, and it was a helpful way for the tutees to overcome hurdles. Methods such as this will not only relieve teachers in the classroom, but at the same time they will easily support children's development.

Author Contributions: Conceptualization, J.K. and M.G.; methodology, J.K.; software, J.K.; validation, J.K.; formal analysis. J.K.; investigation, J.K.; resources, J.K.; data curation, J.K.; writing—original draft preparation J.K.; writing—review and editing, J.K. and M.G.; visualization, J.K.; supervision, J.K. All authors have read and agreed to the published version of the manuscript.

Funding: This research received no external funding.

Institutional Review Board Statement: Ethical review and approval were waived for this study, due to that no personal nor sensitive information that could allow conclusions to be drawn about the persons involved can be found in the study. In addition, there existed no risk but only the opportunity of benefit for the participants.

Informed Consent Statement: Patient consent was waived due to the fact that there is a contract between the cooperating school and the University of Cologne with permission to use data from interventions. Further, no diagnostics were used that do not take place in regular school life. The informed consent process therefore was appropriate and comprehensive for participants as well as custodians.

Data Availability Statement: The data presented in this study are available on request from the corresponding author. 
Acknowledgments: Acknowledgments to the graduate students, who supported the implementation of the treatment, and to Janine Bracht for her second glance on the editing.

Conflicts of Interest: The authors declare no conflict of interest.

\section{References}

1. Ketterlin-Geller, L.R.; Chard, D.J. Algebra readiness for students with learning difficulties in grades 4-8: Support through the study of number. Aust. J. Learn. Difficulties 2011, 16, 65-78. [CrossRef]

2. Watts, T.W.; Duncan, G.J.; Siegler, R.S.; Davis-Kean, P.E. What's Past Is Prologue: Relations between early mathematics knowledge and high school achievement. Educ. Res. 2014, 43, 352-360. [CrossRef]

3. Bowman, J.A.; McDonnell, J.; Ryan, J.H.; Fudge-Coleman, O. Effective Mathematics Instruction for Students with Moderate and Severe Disabilities: A Review of the Literature. Focus Autism Other Dev. Disabil. 2019, 34, 195-204. [CrossRef]

4. Jitendra, A.K.; Alghamdi, A.; Edmunds, R.; McKevett, N.; Mouanoutoua, J.; Roesslein, R. The Effects of Tier 2 Mathematics Interventions for Students with Mathematics Difficulties: A Meta-Analysis. Except. Child. 2020, 87, 307-325. [CrossRef]

5. Cumming, J.J.; Elkins, J. Lack of Automaticity in the Basic Addition Facts as a Characteristic of Arithmetic Learning Problems and Instructional Needs. Math. Cogn. 1999, 5, 149-180. [CrossRef]

6. Fuchs, L.S.; Compton, D.L.; Fuchs, D.; Paulsen, K.; Bryant, J.D.; Hamlett, C.L. The Prevention, Identification, and Cognitive Determinants of Math Difficulty. J. Educ. Psychol. 2005, 97, 493-513. [CrossRef]

7. National Center for Education Statistics. Nation's Report Card. National Assessment of Educational Progress; U.S. Department of Education, Institute of Education Sciences: Washington, DC, USA, 2019.

8. Hopkins, S.; Russo, J.; Siegler, R. Is counting hindering learning? An investigation into children's proficiency with simple addition and their flexibility with mental computation strategies. Math. Think. Learn. 2020, 1-18. [CrossRef]

9. Hopkins, S.; Bayliss, D. The Prevalence and Disadvantage of Min-Counting in Seventh Grade: Problems with Confidence As Well As Accuracy? Math. Think. Learn. 2017, 19, 19-32. [CrossRef]

10. Aud, S.; Hussar, W.; Kena, G.; Bianco, K.; Frohlich, L.; Kemp, J.; Tahan, K. The Condition of Education 2011 (NCES 2011-033); U.S. Government Printing Office: Washington, DC, USA, 2011.

11. National Mathematics Advisory Panel (NMAP). Foundations for Success: The Final Report of the National Mathematics Advisory Panel; U.S. Department of Education: Washington, DC, USA, 2008.

12. Geary, D.C. Cognitive predictors of achievement growth in mathematics: A 5-year longitudinal study. Dev. Psychol. 2011, 47, 1539-1552. [CrossRef] [PubMed]

13. Nelson, P.M.; Parker, D.C.; Zaslofsky, A.F. The Relative Value of Growth in Math Fact Skills across Late Elementary and Middle School. Assess. Eff. Interv. 2016, 41, 184-192. [CrossRef]

14. Musti-Rao, S.; Plati, E. Comparing Two Classwide Interventions: Implications of Using Technology for Increasing Multiplication Fact Fluency. J. Behav. Educ. 2015, 24, 418-437. [CrossRef]

15. Steel, S.; Funnell, E. Learning Multiplication Facts: A Study of Children Taught by Discovery Methods in England. J. Exp. Child Psychol. 2001, 79, 37-55. [CrossRef]

16. Alloway, T.P. Working Memory, but Not IQ, Predicts Subsequent Learning in Children with Learning Difficulties. Eur. J. Psychol. Assess. 2009, 25, 92-98. [CrossRef]

17. Geary, D.C. Development of Mathematical Understanding. In Handbook of Child Psychology; Wiley: Hoboken, NJ, USA, 2007; pp. 777-810. Available online: https://onlinelibrary.wiley.com/doi/full/10.1002/9780470147658.chpsy0218 (accessed on 7 May 2021).

18. Passolunghi, M.C.; Siegel, L.S. Working memory and access to numerical information in children with disability in mathematics. J. Exp. Child Psychol. 2004, 88, 348-367. [CrossRef]

19. Tournaki, N. The Differential Effects of Teaching Addition through Strategy Instruction Versus Drill and Practice to Students With and Without Learning Disabilities. J. Learn. Disabil. 2003, 36, 449-458. [CrossRef]

20. Cozard, L.E.; Riccomini, P.J. Effects of digital-based math fluency interventions on learners with math difficulties: A review of the literature. J. Spec. Educ. Apprenticesh. 2016, 5, Available. Available online: https://scholarworks.lib.csusb.edu/josea/vol5/iss2/2 (accessed on 26 May 2021).

21. Bouck, E.C.; Park, J. A Systematic Review of the Literature on Mathematics Manipulatives to Support Students with Disabilities. Educ. Treat. Child. 2018, 41, 65-106. [CrossRef]

22. Jitendra, A.K.; Lein, A.E.; Soo-Hyun, I.; Alghamdi, A.A.; Hefte, S.H.; Mouanoutoua, J. Mathematical interventions for secondary students with lerning disabilities and mathematics difficulties: A meta-analysis. Educ. Psychol. 2018, 84, 177-196. [CrossRef]

23. Lämsä, J.; Hämäläinen, R.; Aro, M.; Koskimaa, R.; Äyrämö, S.-M. Games for enhancing basic reading and maths skills: A systematic review of educational game design in supporting learning by people with learning disabilities. Br. J. Educ. Technol. 2018, 49, 596-607. [CrossRef]

24. Stocker, J.D.; Kubina, R.M. Impact of Cover, Copy, and Compare on fluency outcomes for students with disabilities and math deficits: A review of the literature. Prev. Sch. Fail. Altern. Educ. Child. Youth 2017, 61, 56-68. [CrossRef]

25. Morano, S.; Markelz, A.M.; Randolph, K.M.; Myers, A.M.; Church, N. Motivation Matters: Three Strategies to Support Motivation and Engagement in Mathematics. Interv. Sch. Clin. 2021, 1-8. [CrossRef] 
26. Hawkins, R.O.; Collins, T.; Hernan, C.; Flowers, E. Using Computer-Assisted Instruction to Build Math Fact Fluency. Interv. Sch. Clin. 2017, 52, 141-147. [CrossRef]

27. Fuchs, L.S.; Seethaler, P.M.; Powell, S.R.; Fuchs, D.; Hamlett, C.L.; Fletcher, J.M. Effects of Preventative Tutoring on the Mathematical Problem Solving of Third-Grade Students with Math and Reading Difficulties. Except. Child. 2008, 74, 155-173. [CrossRef] [PubMed]

28. Grays, S.D.; Rhymer, K.N.; Swartzmiller, M.D. Moderating Effects of Mathematics Anxiety on the Effectiveness of Explicit Timing. J. Behav. Educ. 2017, 26, 188-200. [CrossRef]

29. Duhon, G.J.; House, S.; Hastings, K.; Poncy, B.; Solomon, B. Adding Immediate Feedback to Explicit Timing: An Option for Enhancing Treatment Intensity to Improve Mathematics Fluency. J. Behav. Educ. 2015, 24, 74-87. [CrossRef]

30. Wells, J.C.; Sheehey, P.H.; Sheehey, M. Using Self-Monitoring of Performance With Self-Graphing to Increase Academic Productivity in Math. Beyond Behav. 2017, 26, 57-65. [CrossRef]

31. Weiner, B. Attribution Theory, Achievement Motivation, and the Educational Process. Rev. Educ. Res. 1972, 42, 203-215. [CrossRef]

32. Chinn, S.J. Addressing the Unproductive Classroom Behaviors of Students with Special Needs; Kingsley: London, UK, 2010.

33. Tan, A.; Nicholson, T. Flashcards revisited: Training poor readers to read words faster improves their comprehension of text. J. Educ. Psychol. 1997, 89, 276-288. [CrossRef]

34. Skarr, A.; Zielinski, K.; Ruwe, K.; Sharp, H.; Williams, R.L.; McLaughlin, T.F. The Effects of Direct Instruction Flashcard and Math Racetrack Procedures on Mastery of Basic Multiplication Facts by Three Elementary School Students. Educ. Treat. Child. 2014, 37, 77-93. [CrossRef]

35. Irvin, J.L.; Meltzer, J.; Dukes, M. Student motivation, engagement, and achievement. In Taking Action on Adolescent Literacy: An Implementation Guide for School Leaders; Irvin, J.L., Meltzer, J., Dukes, M., Eds.; ASCD: Alexandria, VA, USA, 2007 ; pp. $27-50$.

36. Christenson, S.L.; Reschly, A.L.; Wylie, C. Handbook of Research on Student Engagement; Springer Science \& Business Media: New York, NY, USA, 2012. [CrossRef]

37. Burns, M.K.; Ysseldyke, J.; Nelson, P.M.; Kanive, R. Number of repetitions required to retain single-digit multiplication math facts for elementary students. Sch. Psychol. Q. 2015, 30, 398-405. [CrossRef]

38. Utley, C.A.; Mortweet, S.L.; Greenwood, C.R. Peer-Mediated Instruction and Interventions. Focus Except. Child. 1997, $29,1-23$. [CrossRef]

39. Mitchell, D. What Really Works in Special and Inclusive Education. Using Evidence-Based Teaching Strategies; Routledge: New York, NY, USA, 2014.

40. Fuchs, D.; Fuchs, L.S.; Mathes, P.G.; Simmons, D.C. Peer-Assisted Learning Strategies: Making Classrooms More Responsive to Diversity. Am. Educ. Res. J. 1997, 34, 174-206. [CrossRef]

41. Delquardi, J.; Greenwood, C.R.; Whorton, D.; Carta, J.J.; Hall, R.V. Classwide Peer Tutoring. Except. Child. 1986, 52, 535-542. [CrossRef]

42. Lo, Y.-Y.; Cartledge, G. Total class peer tutoring and interdependent group oriented contingency: Improving the academic and task related behaviours of fourth-grade urban students. Educ. Treat. Child. 2004, 27, 235-262.

43. Greenwood, C.R.; Terry, B.; Utley, C.A.; Montagna, D.; Walker, D. Achievement, Placement, and Services: Middle School Benefits of Classwide Peer Tutoring used at the Elementary School. Sch. Psychol. Rev. 1993, 22, 497-516. [CrossRef]

44. Dufrene, B.A.; Reisener, C.D.; Olmi, D.J.; Zoder-Martell, K.; McNutt, M.R.; Horn, D.R. Peer Tutoring for Reading Fluency as a Feasible and Effective Alternative in Response to Intervention Systems. J. Behav. Educ. 2010, 19, 239-256. [CrossRef]

45. Alegre, F.; Moliner, L.; Maroto, A.; Lorenzo-Valentin, G. Peer tutoring and mathematics in secondary education: Literature review, effect sizes, moderators, and implications for practice. Heliyon 2019, 5, e02491. [CrossRef]

46. Bowman-Perrott, L.; Davis, H.; Vannest, K.J.; Williams, L.; Greenwood, C.R.; Parker, R. Academic Benefits of Peer Tutoring: A Meta-Analytic Review of Single-Case Research. Sch. Psychol. Rev. 2013, 42, 39-55. [CrossRef]

47. Dennis, L.M.; Canas, M.; Ortega, M.M. Effects of Team Competition Versus Team Cooperation in Classwide Peer Tutoring. J. Educ. Res. 2007, 100, 155-160. [CrossRef]

48. Ginsburg-Block, M.D.; Rohrbeck, C.A.; Fantuzzo, J.W. A meta-analytic review of social, self-concept, and behavioral outcomes of peer-assisted learning. J. Educ. Psychol. 2006, 98, 732-749. [CrossRef]

49. Hayes, J.R.; Berninger, V.W. Relationships between idea generation and transcription: How the act of writing shapes what children write. In Traditions of Writing Research; Bravermen, R.K., Lunsford, K., McLeod, S., Null, S., Rogers, A.S.P., Eds.; Taylor and Frances/Routledge: New York, NY, USA, 2009; pp. 166-180.

50. Haffner, J.; Baro, K.; Parzer, P.; Resch, F. Heidelberger Rechentest (HRT 1-4); Hogrefe: Göttingen, Germany, 2005.

51. Thomas, G.; Dowker, A. Mathematics Anxiety and Related Factors in Young Children. In Proceedings of the 2000 British Psychological Society Developmental Section Conference, Online, 30 June-1 July 2020; British Psychological Society: Bristol, UK, 2000.

52. Gast, D.L.; Lloyd, B.P.; Ledford, J.R. Multiple baseline and multiple probe designs. In Single Case Research Methodology; Ledford, J.R., Gast, D.L., Eds.; Routledge: New York, NY, USA, 2018; pp. 239-282. [CrossRef]

53. Gast, D.L.; Hammond, D. Withdrawal and reversal designs. In Single Subject Research Methodology in Behavioral Sciences; Gast, D.L., Ed.; Routledge: New York, NY, USA, 2009; pp. 234-275. [CrossRef]

54. Tate, R.L.; Perdices, M.; Rosenkoetter, U.; McDonald, S.; Togher, L.; Vohra, S. The Single-Case Reporting Guideline in behavioural Interventions (SCRIBE) 2016: Explanation and elaboration. Arch. Sci. Psychol. 2016, 4, 10-31. [CrossRef] 
55. Wilbert, J. Package "Scan". 2020. Available online: https://www.uni-potsdam.de/fileadmin01/projects/inklusion/scan/scan. pdf (accessed on 26 May 2021).

56. O'Brien, S.; Repp, A.C. Reinforcement-Based Reductive Procedures: A Review of 20 Years of their Use with Persons with Severe or Profound Retardation. J. Assoc. Pers. Sev. Handicap. 1990, 15, 148-159. [CrossRef]

57. Parker, R.I.; Vannest, K.J.; Davis, J.L.; Sauber, S.B. Combining Nonoverlap and Trend for Single-Case Research: Tau-U. Behav. Ther. 2011, 42, 284-299. [CrossRef] [PubMed]

58. Karnes, J.; Grünke, M.; Barwasser, A. The effects of a math racetracks intervention on the single-digit multiplication facts fluency of four struggling elementary students. Insights Learn. Disabil. 2021, 18, 1-25.

59. Erbey, R.; McLaughlin, T.F.; Derby, K.M.; Everson, M. The effects of using flashcards with reading racetrack to teach letter sounds, sight words, and math facts to elementary students with learning disabilities. Int. Electron. J. Elem. Educ. 2011, 3, 213-226. Available online: http:/ / www.iejee.com/index.html (accessed on 26 May 2021).

60. Hopkins, S.; Russo, J. Does (problem-based) practice always make proficient? In 40 Years on: We Are Still Learning! Proceedings of the 40th Annual Conference of the Mathematics Education Research Group of Australasia, Victoria, Melbourne, 2-6 July 2017; Downton, A., Livy, S., Hall, J., Eds.; Merga: Melbourne, Australia, 2017; pp. 317-324. [CrossRef] 